Theo Reeves-Evison

\title{
Deception and Fiction as Forms of World-making in Contemporary Art
}

This article probes the grey area between lies and fiction in order to interrogate the effects such strategies have, both within and outside of the sphere of art. For better or worse, art works that experiment with the methodologies of fiction and deception have the capacity to generate real effects. In this article I propose to focus on two broad classes of effects: those that are somehow critical, that turn our attention back on the truth-framing devices that allowed for deception to emerge in the first place, and those that are inventive, that somehow secrete a new universe of reference. The kinds of epistemological choreography used by artists such as The Yes Men and Dora Garcia do not only expose rhetorical devices and truthframing mechanisms, they also leave a 'residue' of their false content long after their truthclaims have been dropped. In this article I will argue that such works have a germinal as well as a parasitic relationship to truth and are involved in a world-making which is ontologically anterior to codifications of true and false.

Lying has proven to be a surprisingly popular activity among artists in recent years. Over the last few decades projects have included advertisements for non-existent events, invented historical personae, forms of tactical media, imitation newspapers and websites, and a variety of pseudonyms adopted for various purposes. ${ }^{1}$ While this glut of deceptive artworks is relatively recent, it could be seen to build on a longer history that stretches back as far as early forms of camouflage, trompe-l'oeil and quadratura. Arguably what distinguishes recent artistic experiments in this domain from their antecedents is a focus on process, with an eye to managing not only the deception itself, but also the moment when it unravels.

1 To cite a handful of these works, in 2013 the artist Ryan Gander commissioned the advertising agency Kirke and Hodgson to produce a PR campaign for a fictional government initiative to promote imagination, Imagineering. For the 9th Istanbul Biennial in 2005, the artist Michael Blum chose to pay tribute to a little known historical figure called Safiye Behar by mounting a display of letters, books, documents and photographs in her former apartment in the Beyoglu district of the city. In the weeks and months that followed the exhibition it emerged that no such character existed. In 2008, The Yes Men created a 'special edition' of The New York Times bearing the headline 'IRAQ WAR ENDS'. They have also made websites that deliberately imitate those of the World Economic Forum, Apple, Halliburton and others. See http://yeslab.org/museum for a full archive. Countless artists have used pseudonyms for various reasons. In 2009, the Czech artist David Černý invented no fewer than 27 artists who were supposed to have collaborated on the Entropa sculpture unveiled at the headquarters of the council of the European Union. 
The artist Walid Raad writes that "facts have to be treated as processes," highlighting the way they are produced, put to work, made affective, or otherwise challenged and disputed ( $\operatorname{Raad} 2005,121)$. The same could be said for lies. In both cases there is a process that unfolds over time - lies hatch, grow, survive unnoticed or shed their skin of truth. To account for the processual nature of artistic experiments with deception, the art historian Carrie Lambert-Beatty has coined the term 'parafiction', using it to describe artworks that actively dupe viewers, often before self-consciously shepherding them back to reality (Lambert-Beatty 2009). ${ }^{2}$ The question at the heart of this essay is: what remains of the artistic lie once the 'truth' has been restored? Once its object is revealed to be false, a lie does not simply evaporate; it leaves behind it a residue long after its truth-claims have been dropped. For better or worse, artworks that experiment with deception have the capacity to generate real effects. In this paper, I want to focus on two broad classes of effects: those that are somehow critical, that turn our attention back on the truth-framing devices that allowed for deception in the first place, and those that are inventive, that inscribe the image of a possible world onto the mind of the viewer or participant.

\section{From Intention to Effect}

What is a lie in the first place? When it comes to pinpointing a precise definition, the issue of intention quickly comes to the fore. It was St. Augustine who first outlined a systematic theory of lying that rested on the intentions of the liar. In his De Mendacio, he writes that "not everyone who says a false thing lies, if he believes or opines that to be true which he says," thereby arguing that it is not so much the relation between the utterance and reality that characterises a lie, but rather the intention to deceive (Augustine 1847, 383). This position highlights that lying is not so much based on an abandonment of truth (in the narrow sense of epistemological accuracy), but rather an abandonment of truthfulness.

With the category of truthfulness, the emphasis is narrowly placed on the intentions of the liar. A focus on intentions inevitably leads to their schematisation according to a pre-established moral code, giving rise to such categories as 'white lies', 'noble lies' or 'malicious lies', which can be distinguished from one another only if their intended outcome is taken into account.

The moral ordering of lies based on intention could be used to think about artworks such as Dow Does the Right Thing (2004) by The Yes Men. In what is probably the most famous intervention by the group, and a defining example of what has been called 'tactical media', one of the group's members, Andy Bichlbaum, posed as a representative of Dow Chemical for an interview on BBC World T.V. ${ }^{3}$ The interview

2 This article provides an excellent summary of a number of artworks that experiment with truth.

3 The term 'tactical media' was coined at the 'Next Five Minutes' (N5N) conference in Amsterdam in 1993, and subsequently defined by the organisers as referring to "a critical usage and theorization of media practices that draw on all forms of old and new, both lucid and sophisticated media, for 
took place on the twentieth anniversary of the 1984 Union Carbide chemical spill at Bhopal, in India, which killed around twenty thousand people and damaged the health of countless others. As the parent company of Union Carbide since 2001, Dow have continually refused to take responsibility for the environmental after-effects of the spill and have offered no compensation to those still suffering from related illnesses. ${ }^{4}$ It was therefore a surprise to many viewers when on live T.V. a representative of Dow pledged $\$ 12$ billion to make reparations to the victims and clean up the spill site. It took the BBC just two hours to reveal the spokesperson as an imposter, by which time shares in Dow had already dipped on stock markets around the world. ${ }^{5}$

According to a theory of lying based on intentions, this artwork could perhaps be considered to embody an altruistic lie. But what does characterising it as such really achieve? Fundamentally, any schematisation of lies founded on intention simply applies pre-existing moral categories of good and evil to a person or group's presumed motives.

Specific cases of deception rarely yield reliable knowledge of the intentions of the deceiver. With The Yes Men one may be on relatively firm ground in assuming that their intentions were to help victims of the spill, but in the great majority of cases artists' intentions are a lot more opaque. Furthermore, by devoting attention to a moral calculation based on intention the thoroughly ethical stakes involved in artworks that experiment with deception are overlooked. The Yes Men justified their intervention with a phrase associated with the anti-globalization movement at the time: "We were trying to show that another world is possible." An approach geared towards unpacking the ethical stakes of the work would focus less on the intention "We were trying ..." and more on the production of alternative universes of reference (to borrow a phrase from Félix Guattari): "another world is possible". Such an analysis would look at the range of novel effects on the production of subjectivity that an artwork such as Dow Does the Right Thing sets in motion.

To the two broad approaches to the subject of lying already discussed (truth as epistemological accuracy and truthfulness as the product of an imputed intention to be truthful) a third could be added: that of a truth effect. In the field of psychology, the term "illusory truth effect" was first used by Hasher, Goldstein, and Toppino (1977) to describe the increased likelihood of false facts being intuited as true after they had been repeated several times. Here the term could be used in a different sense, inspired by the work of Barbara Cassin. In Sophistical Practice, Cassin focuses on the lines of mutual influence between philosophy and sophistry, claiming that the latter's privileging of rhetorical forms over and above any ontological claims amounts to a privileging of effect over intention:

achieving a variety of specific noncommercial goals and pushing all kinds of potentially subversive political issues" (Critical Art Ensemble 2001, 5).

4 According to the Bhopal Medical Appeal, some victims received between $\$ 300$ and $\$ 500$ from Union Carbide in 1989, worth about five years of medical care.

5 The Yes Men claim on their website that Dow made a loss of 2 billion dollars on the German stock exchange. 
Philosophy never relinquishes its claim to unmask sophistics by banking on the concept of intention; sophistics never ceases to distinguish itself from philosophy by emphasising the accounting of effects. The consideration of effects can match that of intention because the effect is no longer at the mercy of a dichotomy: faced with the polarised duplicity of intention, there is or there is not an effect, de facto, precisely. (Cassin 2014, 40)

Any understanding of intentions is reliant on how they are communicated, and for this reason they are at the mercy of a dichotomy between genuine and disingenuous speech. Effects, on the other hand, are signs of themselves and cannot be falsified. Faced with the inscrutable nature of intentions, this essay wagers that a focus on the effects of artistic practices of deception will be more fruitful. This is not to argue that a definition of lying should be re-founded on the basis of the effect it has but rather that it is more productive to consider the aspects of the lie which become public, participatory, and dialogic. The effects of deceptive utterances are rarely clear-cut. Their edges bleed into the fabric of social life, addressing multiple audiences at the same time, bringing about all manner of secondary and tertiary effects - some intended, others not. By focusing on effects rather than intentions we can better account for the scope of the social domain of which lying is a part.

\section{Intimate Percussion}

In 2005, a strange rumour spread through the Spanish city of León. Groups of young people were increasingly turning their back on conventional music in preference for the sound of their own heartbeat, which was said to have addictive properties. Personal music devices were being modified to amplify the heartbeat of the user and prolonged exposure had the capacity to induce a trance-like state. Signs of this nascent trend seemed to be materializing all over the city: graffiti and posters appeared in public places carrying slogans such as 'intimate percussion', special events were held at local venues, and the story seemed to be gaining traction in the local media as well, with an interview broadcast on radio León and scattered articles in the local press. When the record label 'Musique Camus' gathered together several bands in order to record an album of music entirely inspired by the heartbeat - later reviewed by the music critic Carlos del Riego -, it seemed that the private practice had suddenly developed into a full blown subculture, further bolstered by the website heartbeaters. net, which functioned as an online portal for the growing community.

Although outwardly extreme, the rumour was lent some credibility by a number of existing media narratives. Studies into the effects of repetitive audio on the listener's heartbeat were quoted and circulated as factoids that fed into the rumour. The practice of 'heartbeating' also resonated with a number of technologically alarmist voices that had previously lamented the decline of face-to-face interaction. This decline was linked to familiar narratives of a generational disconnect between a selfobsessed youth culture and an older generation that looked on in dismay. To the latter 
it might have been understandable for music itself to give rise to a new subculture, but the onanistic nature of a youth culture that preferred to get high on their own heartbeats seemed to symptomize a greater range of underlying social ills.

For many, the revelation that the rumour was in fact a work of art by Dora Garcia, who made the announcement on the occasion of her exhibition opening at the Museo de Arte Contemporáneo de Castilla y León (MUSAC), did not come as much of a surprise. This is because many of the participants were enlisted as collaborators some three months before Garcia revealed the work's fictional content. A second group of disbelievers may have had doubts after seeing Garcia's name on the heartbeaters.net website. There, a previous work by the artist on the same theme-Heartbeat (1999), first exhibited at the Centro Andaluz de Arte Contemporáneo in Andalucía - was posited as an originary fiction, which precipitated the real life spread of the practice to urban centres across Spain and beyond. ${ }^{6}$ For a surprising number of others, the fiction had become a reality, and many of those who contributed material to the website heartbeaters.net did so of their own volition, presumably in the belief that just such a subcultural form was in fact emerging.

The project's success lay not only in its ability to play on existing social anxieties but also made use of particular circuits of distribution. Garcia was quick to involve professionals in the fields of music, radio, and TV, who made use of both official channels of communication in the broadcast and print media and propagated the fiction by means of word-of-mouth or 'word-of-web'. Like all rumours, the source of the heartbeater stories in León was obscure and at the beginning lacking in empirical validation. In this way, the rumour existed as an artefact of unofficial speech that once released into the wild began to mutate and have real effects. Here the proximity of Heartbeaters to commercially driven campaigns of a similar character is significant: both seek to insert stories into pre-existing social networks as if they had occurred spontaneously, ultimately with the aim of greater market/audience penetration. Obvious brand authorship notwithstanding, what distinguishes Heartbeaters from such PR practices is that the anonymous, distributed deception was ultimately reigned in and assigned to a specific author with a specific motive. The lie was in effect terminated, only in Garcia's case, at this very moment it assumed the status of a fiction.

Here it is interesting to consider the difference between lies and fiction. While the former claim to describe reality, the latter suspends all claims to this effect, either implicitly or explicitly. ${ }^{7}$ The suspension of these claims frees the work of fiction from any social obligation to be truthful. Just as lies need to take the listener into account, the fictional status of an object is worked out in a dialog between an author, an artwork and its audience according to a shifting set of conventions that change over

6 The original manifestation of the work consisted of a hyperlinked text narrative, posters, videos, and pseudo-scientific reports.

7 This follows from John Searle's definition of fiction as something "made possible by the existence of a set of conventions which suspend the normal operation of the rules relaying illocutionary acts and the world" (Searle 1979, 67). 
time. Heartbeaters played with such conventions, suspending them at a temporal juncture that caused the project to exist at one stage as a lie and at another one as a fiction. As a term that covers both practices at the same time, here the word 'fabulation' could be used to describe the project as a whole. ${ }^{8}$

In order to consider the effects Heartbeaters generated it will be useful to look at the sequential nature of the piece in greater detail. For many participant-viewers the temporal makeup of Heartbeaters involved three stages.

In the first stage, elements of the story were allotted a space within a material network of signs and relayed via circuits of distribution. Here the object of deception had the capacity to be registered as factual and bleed into other epistemological inscriptions and change their experiential qualities, for example bolstering moral panic. During this stage, the antecedent myth of a previous artwork aimed to reinforce the veracity of the piece.

During the second stage, some aspect of the lie was revealed to be factually inaccurate or false. This was set in motion by an element of the artwork itself, and here it could be argued that Garcia's termination of the fictional content can be considered part of the overall choreography. The initial deception subsequently started to unravel and the experiential quality of the object of deception changed.

The final stage would seem to have involved two different processes, which are not mutually exclusive. One allowed the viewer to critically revisit the site of the original deception, in the process reflecting on the range of truth-framing devices that made it possible for the work to be perceived as truth in the first place. The final manifestation of Garcia's project consisted of various didactic elements chronicling events in the life of the artwork, thereby facilitating a critical return to these very devices. In this way Heartbeaters created a discourse on deception, as well as deception itself. This aspect closes the work back on itself, but it also encourages a critical literacy that may be transferred to other objects, giving the unsuspecting participant a crash course in the arts of rhetoric. Nevertheless, and this is the other process involved at this stage, some residue of the original lie may still remain. Even though the lie has been unravelled, it may have slightly changed the objects of knowledge it came into contact with during the first stage.

\section{Talking Back}

The idea that Garcia's work not only has the capacity to sharpen a viewer's critical faculties but also, somehow, leave a 'residue' of its false content even after truth-claims have been dropped points towards a possible effect on the production of subjectivity.

In an essay on the work of Jean Genet, Félix Guattari describes a similar process whereby Genet brings a "dreamer function" to bear on the plight of the Black Panthers and the Palestinians in his last novel Prisoner of Love. Guattari argues that

8 The OED defines the verb "fabulate" as "to relate as a fable or myth" and "to invent, concoct, fabricate" (OED Online, "fabulate, v."). 
Genet's "dreamer function" does not work towards the "derealization of these movements," but "is perhaps even a means of conferring on them a more intense subjective consistency" (Guattari 2012, 221). Although Guattari does not deal directly with deception as it has been discussed here, his argument is significant because it takes us in a different direction from the claims made for the 'truth' of fictive or deceptive art, exposing the ultimate contingency and contextual colouration of discourse. By contrast, here Guattari positions art as capable of augmenting reality and granting it a greater subjective consistency. This is linked to the formation of a collective subjectivity in the groups Genet worked with.

A connection to Guattari can also be established on the basis of his discussion of fabulation, a term first used in a philosophical context by Henri Bergson. In The Two Sources of Morality and Religion, the latter accords fiction the power "to prevent or modify action" (Bergson 1935, 89). For Bergson, this power is a function of what he calls "closed societies". ${ }^{9}$ Myths, gods and "semi-personal powers" play an essentially regulatory function, helping to bind societies together in rigid or static ways. When the concept is taken up by Guattari, both in his solo writing and with Deleuze, the term is largely emptied of these negative connotations. In What is Philosophy?, the authors give the term a decidedly creative meaning, associating it with artists and novelists who go beyond the "perceptual states and affective transitions of the lived." (Deleuze/Guattari 1994, 171). ${ }^{10}$ If for Bergson fabulation is a function that has real effects on society, then for Guattari and Deleuze these effects are no longer linked to static regimes of behaviour, rituals, or structural constants. Rather, the fabulatory function has the capacity to create new models of social interaction that are processual and open. Both in his essay on Genet and his collaborative writing with Deleuze, Guattari explicitly links fabulation to his abiding concern with the production of subjectivity. For Guattari, the fabulatory image effectively "produces the real" (Guattari 2012, 221), at a certain point exceeding the dominant co-ordinates of language to become "self-sufficient, self-referent, self-processual" (ibid., 229). In doing so it becomes an image that can talk back to us.

\section{Lying and Untying}

Early on in Guattari's essay on Genet he zones in on a key visual metaphor from Prisoner of Love. The metaphor involves the vapour from a boiler, which "steams up a window, then gradually disappears, leaving the window clear, the landscape suddenly visible and the room extended perhaps to infinity" (Genet 2003, 367). This image would seem to hint at the power of something less monumental having a fabulatory function: the ephemeral drift of vapour, or the unofficial spread of a rumour. The

9 The French 'fabulation' is rendered as myth-making by Bergson's English translators.

10 The concept of 'fabulation' also appears in a number of Deleuze's solo writings, but is never developed at any length. See Deleuze 1997, 3-4 and Deleuze 1989, 150-154, where it is translated as 'story-telling'. For a detailed discussion of the concept in the context of literature see Bogue 2010. 
sequential nature of the image resonates with the progressive unfolding of Garcia's artwork. If we can align Heartbeaters with this image, we might ask what remains when this 'steam' (or deceptive content) of the work has evaporated. Just as the fabulatory image has the capacity to augment the power of a group, or even "invent a people" for Deleuze $(1997,150)$, perhaps the ultimate constructive effect of Garcia's work is its role in forging the image of a collectivity. However fragile and temporary, the original fiction set in motion a process that produced links between people bound together by the a-signifying rhythms of a heartbeat. The 'revelation' that disbanded this collectivity is effectively what terminates its deceptive content. However, it also had the effect of isolating the work as an object of aesthetic experience, allowing it to speak back to us in a different voice.

By way of a conclusion, we might ask what it is that singles out artworks that employ practices of deception from others that are openly fictitious from the start.

Deception and fiction could be seen as processes of untying and retying respectively. For its part, deception has the capacity to undermine the legality of signification, to distort and disrupt established norms and conventions, and shrug off the obligation to manipulate language in the socially sanctioned manner. In this way deception pulls at the symbolic chord that both helps produce subjects, and knots them together through language.

If deception unties, then fiction reties, and as with any common knot, the retying makes use of the untying. The corrosive effects of deception and the constructive effects of fiction join each other in a double movement of untying and retying. At the same time, deception undermines language in its static mode, something comes to be re-inscribed at the point of collapse. This point of collapse itself becomes a new particularised point of identification, crystallising attention on the 'fabulous image' that comes to be in its place. It draws heterogeneous semiotic materials into its orbit and slowly these give it a consistency that grows and changes with each new addition. Once a certain threshold of consistency is achieved the fiction has the power to talk back to us. This only occurs if the mechanisms of deception are revealed in direct or indirect ways. If specific acts of deception go unnoticed, no specific act of destabilisation occurs, and no aesthetic object is isolated. Deception can serve as a prefatory stage in the deployment of a fabulatory image. Fiction is charged with a power from deception and unstable admixtures between the two have the capacity, for better or worse, to have real effects. 


\section{References}

Augustine of Hippo (1847): On Lying. In: Seventeen Short Treatises of St. Augustine. Oxford: John Henry Parker, 382-425.

Bergson, Henri (1935): The Two Sources of Morality and Religion. Trans. by R. Ashley Audra/ Cloudesley Brereton. London: Macmillan.

Bogue, Ronald (2010): Deleuzian Fabulation and the Scars of History. Edinburgh: Edinburgh University Press.

Cassin, Barbara (2014): Sophistical Practice: Towards a Consistent Relativism. New York: Fordham University Press.

Critical Art Ensemble (2001): Digital Resistance: Explorations in Tactical Media. New York: Autonomedia.

Deleuze, Gilles (1989): Cinema 2: The Time- Image. Trans. by Hugh Tomlinson/Robert Galeta. Minneapolis: University of Minnesota Press.

Deleuze, Gilles (1997): Essays Critical and Clinical. Trans. by Daniel W. Smith/Michael A. Greco. Minneapolis: University of Minnesota Press.

Deleuze, Gilles/Guattari, Félix (1994): What is Philosophy? Trans. by Hugh Tomlinson/Graham Burchell. New York: Columbia University Press.

Genet, Jean (2003): Prisoner of Love. Trans. by Barbara Bray. New York: New York Review of Books. Guattari, Félix (2012): Schizoanalytic Cartographies. Trans. by Andrew Goffey. London: Bloomsbury. Hasher, Lynn/Goldstein, David/Toppino, Thomas (1977): Frequency and the Conference of Referential Validity. In: Journal of Verbal Learning and Verbal Behavior 16 (1): 107-112.

Lambert-Beatty, Carrie (2009): Make-Believe: Parafiction and Plausibility. In: October 129: 51-84.

OED Online: “fabulate, v.", Oxford University Press. http:/www.oed.com/view/Entry/67410 (last accessed 1 September 2015).

Raad, Walid/The Atlas Group (2005): Untitled Artist's Statement. In: Frits Gierstberg, et al. (eds.): Documentary Now! Contemporary Strategies in Photography, Film and the Visual Arts. Rotterdam: NAi, 121-122.

Searle, John R. (1979): Expression and Meaning: Studies in the Theory of Speech Acts. Cambridge: Cambridge University Press.

The Bhopal Medical Appeal: Union Carbide's Disaster. http://bhopal.org/what-happened/unioncarbides-disaster/ (last accessed 1 September 2015).

The Yes Men (2004): Dow Does the Right Thing. http://theyesmen.org/hijinks/bbcbhopal (last accessed 1 September 2015). 